\title{
$\boldsymbol{K} \boldsymbol{O} \boldsymbol{E} \boldsymbol{R} S$
}

DEEL XXVIII

No, 2 .

\section{IETS OOR DIE ONTWIKKELING VAN DIE KARAKTER VAN DIE PERSOONLIKE IN DIE JONGER AFRIKAANSE DIGKUNS.}

Waar my opdrag enigsins vaag was en dit moeilik was om aan te sluit by die drie voordragte wat ek vanoggend eers gehoor het, het ek gebruik gemaak van die vryheid wat die voorsitter my toegestaan het, om die onderwerp waar. oor ek 'n paar gedagtes sal uitspreek, te formuleer soos bo angegee.

Daarvoor sal 'n kort historiese inleiding nodig wees.

Wanneer ná die Engelse oorlog ons ineens die verrassing beleef van 'n eie digkuns, is daardie poësie in wese liries, persoonlike klag en jubilering, al is aanvanklik veral die oorlogsmart die bron van inspirasie en al bereik Leipoldt al dadelik in sy dramatiese monoloë en in die skrynende spot en ironie van sy oorlogsverse 'n groot mate van objektivering.

Daar is die groot eensame, Eugene Marais, wat weerloos teenoor die lewe staan en sy droefgeestige stomminge in suiwer artistieke vorm vergestalt. Dit begin met sy „Winternag", wat ook gesien kan word as vertolking van sy volk se gevoel van verslaenheid; is die onvolprese Boesmanliedjies nie ook, miskien onbewuste, objektivering van eie vereensaamdheid nie? Sy hygende doodsverlange beluister ons in daardie wonder van die helder woord „Diep Rivier", wat hy oorspronklik in die mond van die tragiese karakter in een van sy mooiste verhale lê:

O, Diep Rivier, O Donker Stroom,

Hoe lank het ek gewag, hoe lank gedroom,

Die lem van liefde wroegend in my hart?

- In jou omhelsing eindig al $\mathrm{m}$ smart;

Blus uit, O Diep Rivier, die vlam van haat; -

Die groot verlange wat my nooit verlaat.

Ek sien van ver die glans van sta:1 en goud,

Ek hoor die sag gedruis van waters diep en koud;

Ek hoor jou stem as fluistering in 'n droom,

Kom snel, O Diep Rivier, O Donker Stroom. 
Naas hom staan die Driemanskap, wat begin as bevrydende vertolkers van die oorlogsmart, elkeen vanuit eie lewensiening en in eie stylaard; ook as gevoeliges vir die skoonheid van eie natuur, Totius vir die nederige sinvolheid daarvan. Al gou verwoord hulle eie, individuele worsteling met die lewensprobleme. By Celliers kom dit selde verder as nie erg ontroerde mymering oor die raaisels nie; by Totius is dit tere klag en die innige fluistering van die siel wat berus in die Raadsplan van God. Hoewel teer persoonlik belewe, voel hy sy smart en troos aan as iets wat hy in die geloof deel met al Gods kinders van alle tye. By Leipoldt bly dit magtelose opstand en twyfelvrae, met moedige aanvaarding van die lewe as taak.

Hierdie digters reik vanuit die geestelike verwerking van die volksgebeure en van persoonlike leed en stryd, nietecnstaande 'n groot mate van tyd-en plekgebondenheid, tog telkens uit na iets van alle tye en alle volke.

In minder mate kan dit gesê word van die volgende geslag, die Twintigers, w.lt uiting wil gee aan hulle Sturm-und Drang. By die swakkeres bly dit stemrningsgediggies en liefdesliedjies (Fagan, Keet, Kleinjan). Wassenaar bereik in sy beste verse iets meer gedraens maar priát meer oor kosmiese gevoel as wat hy dit werklik beleef. By Toon van den Heever vind ons voortsetting van Leipoldt se opstand en twyfel, wat verhard tot sinisme.

Dan kom ons by die Dertigers, en hier beg'n ons eintlike onderwerp. Hulle het opgegroei in 'n tydperk van belangrike groei en gebeurtenisse. Hulle is daarvan tegelykertyd die vrug en die uiting. Dit jare vanaf 1910 word gekenmerk deur 'n merkwaardige groei van wat ons sou kan noem die Afrikaanse Gedagte. Oor die verrassende tempo waarmee die offisiële taalstryd gewen is, hoef ek seker nie uit te wei nie. Ook nie oor die snelle ontwikkeling op politieke gebied, die Afrikaner se verowering van 'n belangrike plek in die staatsdiens nie. Behalwe in die nywerhede en in die handel begin die droom van S. J. du Toit van die Afrikaner wat op alle gebiede self die voortou neem en nie meer afhanklik is van buitelanders nie, nie meer so onwesenlik lyk nie. Maar veral op kulturele gebied sien ons belangrike groei. Die Afrikaner het deelgenoot geword van die Westerse denke. $\mathrm{Hy}$ begin vry te raak van die fnuikende geestelik-koloniale kompleks. $\mathrm{Hy}$ is nie meer lid van 'n tipiese gemeenskap wat Europa in vertraging te sien gee nie. Hy voel hom, in die woorde van Van Wyk Louw, moderne mens in Afrikaanse gedaante. $\mathrm{Hy}$ is hom bewus daarvan dat hy deel het aan die Westerse beskawing, 'n eiesoortige uiting daarvan is en 'n eie bydrae daartoe moet lewer.

As hy nou kennis neem van die kultuur, die denke, die kuns van sy stamlande, is hy nie meer vyftig jaar agter sy tyd nie, maar het hy kontak met sy tydgenote, veral in Nederland en Engeland - sy belangstelling strek verder: ons merk selfs aanraking met die Franse en Spaanse lewe en kuns. Hierdie kontakte en invloede is lewewekkend vir sowel geesteslewe as vormgewing.

Die digkuns van "Dertig" is verwyt dat dit al te sterk 'n egosentriese kuns was, los van die volkslewe. Ek herinner 
my 'n kritiek van D. F. Malherbe in „Die Volksblad" waarin hy kla dat in so 'n ernstige tydsgewrig (dit was die jare van depressie, afstapping van die goudstandaard, koalisie en samesmelting) digters slegs kon kla oor hulle sieltjies se kwellinge. Heetemal sonder grond was hierdie kritiek miskien nie. Daar is in die eerste verse van Dertig, soos in alle jeugpoësie, ongetwyfeld heelwat troebele selfbejammering, selfs 'n mate van narcissisme. Dit was ook te verwagte by bewuswording van die jeugdige enkeling in sy vereensaamdheid tussen die massa wat die verstedeliking meegebring het. Hierdie bewuswording van die jong Afrikaner in die stadslewe spreek ook uit die invloed wat ons by enkeles merk van die produkte van oorbeskawing, Villon en Baudelaire.

Die kritiek van daardie tyd en ook nog jare daarna het egter enkele belangrike feite nie besef nie:

1. Dat hierdie digters geleef en geskep het uit die oortuiging dat die kunstenaar, ook in sy volksverbondenheid, tot selfverwesenliking kan kom slegs deur die verwesenliking van sy individuele aanleg.

2. Dat die „nasionale" in die kuns nie noodwendig bestaan in die ,besing" van die tyd-en plekgebcndene, van spesifieke helde of gebeurtenisse of motiewe nie; dat die romanties-vaderlandse verheerliking van ossewa, gebaarde Voortrekker met voorlaaier, en dapper burger met opslaanhoed, mauser en bandolier selde die diepste wese van die nasionale raak; dat hierdie geslag op heel ander wyse in eie taal en denkvorme uiting gee aan volksverbonden- heid en aan 'n besef van nasionale geroepenheid.

3. Dat hoe revolusionêr dic nuwe generasie ook voorgekom het en ook grotendeels was, dit in belangrike mate die kontinuïteit met die vorige geslagte bewaar het, veral met die Driemanskap. Om slegs een sterk voorbeeld te noem: Van Wyk Louw se koorspel Die Dieper Reg vertoon, by alle verskil van lewensbeskouing en stylaard, verrassende verwantskappe met Rachel, selfs cnkele gevalle van direkte invloed van woord en beeld. En watter diepe besinning op die belang van die smartlike lyding in ons volksgroei, watter dinamiese roepingsbesef spreek daar uit die jonger digter se „By die Monument", waarvan ek die slot aanhaal:

Hier sal ons kniel, hier sal ons bid en peins

tot smartlik in ons leef die pyn jul aangedaan,

tot ons rein word en sterk om n:? terug te deins

vir sterke dinge; dán het ons jul dood verstaan:

Geen smart gaan ooit verlore, want verborge soos die saad

en ingebind tot streng verbeide en verwagte

groei dit in duistere geduld deur baie nagte

tot die dag-helder vreug van ons opstand teen die kwaad.

Die stukrag tot die vernuwing wat die Dertigers gebring het, was hulle individualisme. Al dadelik merk ons dit by die twee oorgangsfigure. I. D. du Plessis se Stryd verbeeld in nog 
retoriese verse die nie beslegte stryd tussen die gees en die demone van die vlees. C. M. van den Heever se poësie is subtiele mymerstemminge oor verganklikheid en dood. As ek meer tyd tot my beskikking gehad het sou ek graag nader aangetoon het hoe dit tot openbaring kom in W. E. G. Louw se verse van sensitivistiese verfyning en dralende beweging, nie altyd vry van 'n sekere estetisisme nie, ook in sy minder suiwer belydenisgedigte van heroïese individualisme, wat destyds veral hoog aangeslaan is. By die swerwer in die kultuur en kuns van baie lande, Uys Krige, in die ligte ironie van sy praatvers en in die Romaanse weemoed oor die verganklikheid van die lewe. In Elisabeth Eybers se poësie hoor ons vir die eerste keer die stem van die jong meisie in haar geestelike verwarring nadat sy ineens oorgeplant is in die sfeer van die kosmopolitiese goudstad, die eerlike bieg, hoewel nog in onsuiwer verse, van jeugdige hunkering, fisies en psigies, na die liefde.

Die stukrag van die vernuwing, die individualisme, kan egter ook 'n gevaar wees, 'n gevaar waarop Nijhoff in sy geestige verhaal „De Pen op Papier" die Rotvanger van Hamelin laat wys met die waarskuwing: „Ik zal je aanraden voorlopig als volgt te beginnen. Beschrijf alleen gewaarwordingen van andere menschen. Medegevoel is geen moreele plicht, het is een aangeboren hartstocht en vindt zijn oorzaak in de aantrekking die magnetisch alle vleesch verbindt. Ten bate van jezelf, ontwikkel dien hartstocht, maak je hem bewust, en den': en leef in andermans gevoel. Zoo alleen kom je van jezelf vrij. Als dit te langzaam gaat, houd dan een dagboek bij, en schrijf, iederen keer dat het je weer overkomt naar je eigen gevoel te Iuisteren, neer wat je invalt en dat dan met zooveel mogelijk durf, overdrijving, literairen wellust en zelfbeklag. Wanneer je echter den versvorm opneemt: aleen het gevoel van anderen ... Wees voorzichtig, of uw stem schroeit door; wees uiterst voorzichtig, of ge verliest de gehele wereld en wat zij waard is, om in den eersten tijd van uw ontroeringen verzen te maken. Heb er dat niet voor over. Wacht tot ge vrij zult zijn, wacht tot ge een vreemdeling voor uzelf zijt geworden, tot gij als het ware een dubbel leven gaat voeren. Er komt voor ieder een tijd dat een mensch zichzelf ziet wegwandelen uit zijn eigen leven. Maar dat moment komt voor velen pas laat, laat in het leven, als het reeds tegen het einde loopt."

Die Dertigers het nie bly vassteek in 'n individualistiese stemmingskuns in egosentriese selfbelydenis nie. Hulle poësie verwy en verdiep tot deernis met die medemens, dit groei tot positiewe lewensbeeld, waarin by sommige die religieuse, 'n weerbare, konstruktiewe denke 'n belangrike rol speel.

Hierdie uitstyg bo die bloot persoonlike sien ons by W. E. G. Louw bv. in sy „Ou-volkies" en in sy Bybelse sonnette; by Uys Krige in die wrange ballade „Romanza”, in sy magtige „Lied van die Fascistiese Bomwerpers" en in sy oorlogsgedigte. Elis. Eybers se jeug klagte verdiep al gou tot die "stil avontuur" van verwagting en vervulling van moederskap, belewe vanuit die biologiese 
wonder. Daarna word dit konflik tussen lewe en dood, tussen hart en verstand. Sy vertolk nie die verlangens en konflikte van een toevallige vrou, Elis. Eybers, nie maar van dié vrou, dié moeder. En tot haar skoonste verse behoort haar "gestaltegedigte", waarin sy die leed van ander verbeeld, soos ook die geval is met C. M. van den Heever.

Die hoogste vervulling van die Dertiger-opvatting van kuns is $\mathbf{N}$. P. van Wyk Louw. Niemand van sy tydgenote het so hoog, op so boeiende wyse uitgestyg bo die persoonlike nie. Hy kom selis tot verontpersoonliking. Daarom moet ons by hom langer stilstaan.

In sy eerste bundel, Alleenspraak, is hy die opstandige enkeling, wat soek na sy plek in die ewige orde. Telkens gryp hy ' $n$ ander denkstelsel aan om gestalte te gee aan sy steeds veranderende lewensbeeld: die panteisme, Nietschziaanse individualisme; hy kom onder invloed van die Duitse ekspressionisme en eindig met die irrasionalisme te aanvaar:

Ek wou U liggaam sien en gryp, ek wou die see vang in my net; ek wou $U$ mag vang, vang en bind met koperlsettings van my wet.

Dan wou ek in my glorie troon, my hof by winde en sterre hou; ek wou met ewig-stille oë op U en op U knegskap skou.

So sien hy die rasionalistiese strewe om alles, selfs God, te verklaar. $\mathrm{Hy}$ breek met hierdie dwaasheid:
Vir my die kruis en doringkroon, die reise wat geen einde het, vir my die soek wat nimmer vind, vir my die sterre sonder wet.

O God, vir my die wilde sin, die oë wat hul waansin noem, om wat ondenkbaar is, te dink, en wat onmoontlik is, begin.

Ek sal ons Wete stukkend skeur en uitstrooi tussen sterre en maan! Sal ek met so 'n flenterkleed $\mathrm{U}$ weë, O God, U weë gaan?

So sal 'k met naakte liggaam stap die reis van hierdie wonderlewe, met wonderoë in die lig wat om my van U glorie bewe.

Daar is één heerlikheid: $U$ sien; daar is één rus: om $U$ te soels; om nie te weet - dit is $U$ seën; en om te vind - dit is U vloek.

U sien dit: hoe individualisties hierdie poësie ook is, hoe vol nog van vitalistiese trots, dit gaan nie om die eie persoon nie, dit gaan hier om 'n sterk persoonlike soeke na wat buite die persoon lê, na God.

Twee jaar na die nog skrille en eksperimentele „Alleenspraak" verskyn Die Halwe Kring. Dit bring 'n verrassende ontwikkeling van geestelike groei en van vormgewing. Die digter is ook hier nóg lirikus, maar met 'n vaster, voller, universeler geluid. Die twee dinamiese stukragte is sy vitalisme en sy irrasionalisme. In die dramatiese monoloog Die Profeet is die digter die deur 'n irrasionalistiese God onder die mense 
uitgesonde profeet, nog sterk individualisties naar Godgeroepe:

Hul noem dit waansin as ek skreeu en lag

en vreemde woorde praat oor hulle troos.

$\mathrm{U}$ liet geen kenbare teken aan my of aan my woord

gesit as borg van wat $U$ deur my spreek;

U gésel my met hulle luide hoon;

ek moet die bitter brood van twyfel eet

en daeliks weer my vlamme-waarheid gryp -

maar ek, aan wie $U$ self $U$ werk verklaar het,

gaan dán met die nuwe heilige wete uit:

dat hierdie duisternis van my $U$ lig

en waarheid is, hierdie verwarde spraak

U suiwer en deursigtige woord en $\sin$;

dat al my onrus is die saamwaai met

$\mathrm{U}$ magtige wind -

en Heer, ek staan weer sterk

in die andere genade wat $U$ gee.

Die magtige himne Aan die Skoonheid eindig net die versoening:

hoe sal ek dwaas die laaste woorde sê v.t onuitspreeklike dinge waag: dat $j y$ in ons

- wat anders donker is en sonder $\sin -$

dic kringloop en die sin van die heelal voltooi.

As ons jou sien volkome, word alles wyd;

dan straal geheimloos en deurskyn die wêreld op soos somerdae bo die hoëveldsrand, en weet ons diep: God het een oomblik opgehef

tot tydeloosheid en deur ons sterflike oë

Sy ewige wese en Sy eie vreug aanslrou.

U merk die sterk panteïstiese inslag.

Die vitalisme en irrasionalisme stu ook deur die nasionale gedigte in die afdeling „Cedagtes, Liedere en Gebede van 'n Soldaat", net soos in die vervolg daarop: Dic Dieper Reg.

Die digter, 'n klein groep uitverkorenes as geestesaristokrate wat die hoë lewenswaardes as kostelike skat veilig deur die skare moet dra, die digter as profeet, as soldaat op wag - dit is 'n kernkonsepsie vanaf sy eerste jeugwerk, gevoed deur Carlyle en die Duitse romantici, in Louw se kuns, ook in sy dinamiese essays, veral in Lojale Verset.

Interessant is die volgende uitspraak van Louw in 'n Stellenbosse rede van 1936: ,'n Volksliteratuur kan nooit wegkom van die swaar stryd van die denk nie. Ons tegniese geskoolde filosowe steur hulle nie aan die letterkunde nie, en ons skrywers steur hulle nie aan die wysbegeerte nie. En tog is in elke groot kunswerk 'n staalharde struktuur van die denke verborge, is elke groot kunswerk die volmakte formulering van 'n lewenshouding wat ook intellektueel deurworstel is. Met die opraap van „stemmings" vir 'n vers, met die soek na 'n ,tipiese brokkie" vir 'n beskrywing word nog geen volksliteratuur gemaak nie. Die eerlike, strenge deurdink van die moderne lewe, soos uit ons 
nasionale standpunt gesien, met behulp van die groot wysbegeerte van alle tye moet die grondslag van ons kuns wees".

Aan sy eie poësie lê 'n dinamiese, staalharde denke ten grondslag. $\mathrm{Hy}$ is self 'n geskoolde filosoof. Dit wil nie sê dat sy poësie wysbegeerte in versvorm word nie. Sy hele persoonlike déurdink op wat hy in die stelsels van groot. filosowe gevind het, ontvonk sy verbeelding; die gloed van vormskeppende ontroering slaan daaruit op.

Dit sien ons veral in sy Gestaltes en Diere, die merkwaardigste digbundel wat nog in Afrikaans verskyn het en warin ons duidelik die invloed sien van die denke van Hegel en sy skool. Louw het hom hier heeltemal los gemaak van die liries-pesoonlike. Die gedigte handel oor die persoonlikheid in sy diepste geheimenisse maar as objek. Hy betrag los van homself wat hy in eie psigiese lewe ervaar het. In aansluiting aan Hegel se filosofie sien hy die mens as deel van 'n God wat Hom in sy eie "skepping" uitgestort het en saam met sy "skepsel" terug ontwikkel na Homself toe. In daardie ontwikkelingsgang is die Bose die dryfkrag. Hy volg die mens en God op die voet, betrek telkens die gestalte wat hulle verlaat het vir 'n verdere stadium. Maar in die mens wat vanuit die anorganiese oor die biotiese tot gees gegroei het, bly die vorige stadia as aktiewe relikte werksaam en is ' $n$ dreigende gevaar om hom weer terug te trek, soos gebeur in Raka.

Die hewige spanning waaraan hierdie poësie ontspring, gee die digter self weer in sy Renboot:
My boot skiet rasend oor die see, die vrees vlieg soos 'n wit voël mee: moet hy nie sink as hy gaan staan? (iets donkers gryp-gryp onderaan).

My vaart is wankel ewewig tussen swart see en hoë lig.

Die duidelikste kom hierdie konflikterende lae van die persoonlikheid tot openbaring in die desintegrasie van die roes of die waansin. Ek wens dat ek nader met $u$ kon ingaan op al die dramatiese monoloë en sogenaamde ballades van hierdie bundel: Ballade van dic Bose, waarin die Bose met dodelike mefistofeliese dialektiek die mens plaas voor die onontkombare feit dat hy met hom verstrengel is; die dramstiese monoloog van godsdienswaansin, Die Hand van God, waarin die Inkwisiteur geteken staan in sy verwiklielde sielelewe waarin soveel lae van sy persocnlikheid werksaam is: cerlike stryd vir die ou geloof teen die humanisticse gees van die eeu, stryd teen die donker, duiwelse twyfel in homself, lileinlite jaloersheid op sy slagoffer se kalme versekerdheid, skynheiligheid, sadistiese lus tot foltering wat tegelykertyd selffoltering is; of die deels humoristiese, maar diep onder verskriklike belewinge van Die Drinker in sy Kroeg; die laaste van hierdie magtige gedigte is Die Swart Luiperd, weer verbeelding van die waansin, nou van tot mistiek groeiende aardbesetenheid, van die verborgenste lewe in die onderste lae van die persoonlikheid, met volkome vereenselwiging daarmee - want ons het hier nie te doen met geversifieerde Freudi- 
aanse dieptepsigologie nie, die digter daal nie in die dieptes af met die lampie van die bewussyn om hierdie onderbewuste verskynsels te betrag nie. Dis een felle beléwing daarvan, en dit groei tot 'n grootse metafisiese siening van dinge wat in hulle donkerheid 'n diepe straling besit:

'n wêreld het in my verstar:

plant, dier en mens - in die diep swart glas

waar alles enkeld en ontwar

maar klein en mateloos glansend was -...

geen ding is duister, maar hy glans of hou sy skittering ingesluit, en niks is dood, en alles dans en reik na namelose dinge uit.

Waar Leipoldt en Toon van den Heever nie verder gekom het as magtelose klag nie, met hier en daar vae deurskemering van die besef van diepere wetmatigheid, kom die hewigindividualistiese en opstandige digter van Alleenspraak tot hierdie bo-persoonlike, of moet ek liewer sê: verontpersoonlikte kuns?

Sy jongste twee digwerke bring 'n duidelike kentering.

Dis eerstens die hoorspel Dias. Die eersugige seevaarder wil om eie eer die cerste wees om Gods kruise na die verste lande te dra. Hy gaan daarvoor dwars teen die "redelikheid" van sy meciebevelhebber en die bemanning in, wil selfs God tot 'n teken dwing, maar hy moet omdraai. Twaalf jaar later is hy kaptein in die vloot van 'n ander admiraal. Da Gama het die seeweg na
Indië gevind. Sy skip word deur 'n storm oorval. In die aangesig van die dood spreek hy hierdie laaste woorde:

En nou's dit stil en keer ek tot die tyd

terug, en wend my van die tyd, want nie

meer sal ek strewe of begecr; $c n$ hierdie

waters op die middag wat die sterwe in die oomblik van my insig aanbring, sluit my uiteindelik af, en is my teken,

ná die jare, dat ek nie vergeet

en onvoltooi gelaat is, of voltooi

deur eie drang of dwaasheid nie, maar uit

die kern geryp. Nou kan ek bid. God, hou

in hierdie laaste oomblik my gebed gesuiwer soos dit nooit was in my dae;

vergeef my sonde, want aan my was áls onwaar, onheilig, en besmet: tót ook my bid, tót ook my noem, o Heer,

van $U$ en van $U$ heilige Naam onrein :

leer $U$ my bid; bid, bid $U$ self in my, en laat my dank dat $U$ my vasgekeer het en gevang, dat $U$ my hart se sin geweier het tot op sy sterwensuur; dat $U$ tot op die laaste onvervul en onvoltooi gelaat het, God, dié hart wat ek wou vul; dat ek my aan geen werk

ooit kon versadig; dat ek barre kuste en leë lande alleen kon kry.

En wees

by dié land, by daardie eensaam land 
wat ek gevind het ... nie wou vind nie -

net

om my smart; en wees by alle eensaam

dinge, en dië wat eensaam sterwe hier

rondom my; en wees, my God,

tot in die laaste skrik nog hier by my.

Die vitalis en irrasionalis Dias is gebreek tot deemoed, het hom volkome, onvoorwaardelik oorgegee aan God.

In die bundel Nuwe Verse kom die belange gedig Beeld van 'n jeug: Duif en Perd voor. Die digter teken homself as kind, besig om oor 'n geskiedenisboek te peins, terwyl die pragtige hings en die spel van die duiwe in die son, beelde van lewensdrif om hom heen op die werf, telkens sy aandag aftrek. Hy peins oor al die offers waarvan hy gelees het: by die Asteke, die Romeine, Abel, Isak,

Dan op 'n laaste klipkop buite die stad

drie kruise oor 'n land wat donker raak,

en, eindelik, 'n vrye sterwe - en die vermoede:

dalk het dit daardie son kon donker maak

sonder verduistering agter 'n maan van klip;

omdat die aarde en elke aardgebeurtenis

en die son self, en tot die verste ster, tesame net een groot vertelsel is oor Hom en ons, en deur Hom self vertel -

vol beeld, prefigurasie, voorbereiding op een voleindigende slot en dat in elke eeu die-laaste ding verwysing na Hom was, deel van sy Naam ...

Ons agterplaas se gruis die glinster blou,

my vingers trek 'n driehoek om 'n kring

en streel dit uit en aarsel om te hou.

Vroeg in die jare veertig kom 'n nuwe geslag op, weinig jonger as hulle voorgangers op wie hulle voortbou. Wat nie wil sê dat hulle blote epigone is nie. Hoewel hulle deel in die emansipasie van die gevoel, die sinne en die denke wat die Dertigers gebring het, vind ons by hulle tog 'n nuwe toonaard, 'n sekere afkerigheid van die romantiese, iets hards, saakliks. By die faktor van steeds toenemende verstedeliking moet ons hier seker ook rekening hou met kultuurinvloede van oorsee, veral deur immigrasie. Hulle staan ook onder ander literêre invloede.

Die een sterk figuur onder hulle, saam met Van Wyk Louw ons sterkste en oorspronklikste digter, van lg. in menige opsig die antipode, is Dirk Opperman.

Afgesien van 'n groepie minder belangrike gedigte in sy eerste bundel is Opperman van die begin af nooit liries nie. Sy, ook sterk metafisies gerigte, kuns word besiel en beheers deur die drang tot eties-religieuse besinning. 'n Student van ons inrigting, dr. P. D. van der Walt, het verlede week die doktorsgraad ontvang op 'n proefskrif oor 'n kernaspek van sy kuns: sy besef van die kunstenaar se geroepenheid om die gee; te verlos uit die stof, die engel uit die 
klip. Dit kan die digter volgens hom alleen doen deur volkome vereenselwiging met alles, al die harde, aardse, selfs banale dinge van die konkrete werklikheid. Só alleen kan hy die mens, die skepping, sy volk red. Hy is soos die Scriba van die Carbonari:

Ek moet my land, wat buite die hemele lê,

deur Sy genade en Sy meegevoel bestendig in my volk se taal en sê wat $m y$ aangryp; en in volstrekte vereenselwiging met alles om my heen :

bloeisels, Alpe en viswyf, verlos ek deur die gedig die engel uit die steen.

En teenoor die werk van die skepper stel hy dié van die digter wat die gees weer bevry:

Maar ék verlos die mens en hierdie land

volgens 'n ander alchemistiese verband

tussen ons duister gees en $U$, my God,

as ek patrone skep van myn en krot, van kiepersol, swart trossies nastergal

en kwarteltjies wat dans - so die heelal

met mens, agaat en boomsalmander deur die toorklip van die woord verander.

Só beeld hy die werklikheid om hom heen uit: hard, kantig, saaklik, in 'n vers waarin die ekspressiemiddel nie musiek, weelderige ritme is nie maar waarin die spanninge verbeeld word deur drastiese aksente, pregnante alliterasie en rymwoord, 'n suggestiewe spel van simbole en simboolkerne. Die harde aardse ding is tegelykertyd ding en beeld. Alles wat hy met sy ryk verbeeldingskrag betrag het, bybelverhale, fantastiese heiligelegendes van Sinte Brandaan en Christina de Wonderbare transponeer hy tot die vlak van hedendaagse Afrikaanse werklikheid maar tegelykertyd tot iets universeels, iets van alle tye en volke. Dit gaan met hom soos Jorik in die bus in Kaapstad:

Hy weet met die weerkaatsings in die ruit

vlakke van beclde skuif deur alles heen

en niks is in sy tyd en stof gesluit maar alles stroom deur grens en eeu aaneen.

Die verhaal van die diamantsmokkelaar in Brakfontein wat moord pleeg, groei uit tot die besef:

Maar boos bly boos in Brakfontein of Neo-Baäl,

en goed is goed by Golgotha of Brussel;

en deur die eeue is dit reeds bepaal: die plek en spelers sal voortdurend wissel

maar die spel word telkens in die tyd herhaal.

So slaan uit die harde, skynbaar so kale verse 'n visionêre gloed op.

Ek mag my nie laat verlei om op allerlei aspekte van hierdie boeiende kunstenaar in te gaan nie. Laat ek slegs dit beklemtoon: wel sê hy in die bo aangehaalde verse: ek moet bestendig en sê wat my aangryp, maar of hy in Negester oor Ninevé, opgeskrik deur die verwagte geboorte van 'n seun, wat hy sal moet lei "deur die ongekaarte lande van die gees", hom rekenskap gee 
van eie metafisiese lewensbeeld; of hy in Joernaal van Jorik die verhaal vertel van die spioen wat deur 'n duikboot aan wal gesit word om in hierdie land sy taak te verrig, maar met die vaste wete dat hy onverbiddelik en onverwags terug gehaal sal word na sy vaderland, 'n figuur wat simbolies word van die kunstenaar, die mense wat na SuidAfrika gekom het, die ganse mensheid; of hy hom in Engel uit die Klip veral besin op die taak van die digter; of hy in Blom en Baaierd die oral aanwesige teenstelling teken tussen die reine diamant en die baaierd waar dit uit te voorskyn gehaal is, tussen beskawing en barbarisme, orde en chaos as uiterlik teenoor mekaar staande of subtiel verstrengelde magte - dit gaan ook by Opperman nie om die eenling, nie om sy individualistiese self of die van 'n ander nie. Dit gaan om sy volk, om die mensheid, om roeping en roepingsversaking, om die ewige metafisiese wette, om die geroepenheid van die kunstenaar. Opperman is tereg die gewete van sy volk en sy tyd genoem.

In Droogte bid hy:

Dissel en doring en koüngklip, grys is die wêreld en die kraaie krys hou in my hand die wiggelroede wat $U$ waters wys.

Ek weet nie of ek aan die opdrag van die bestuur voldoen het nie, ook nie of ek aan die verwagtinge van my gehoor beantwoord het nie. Ek hoop slegs dat ek enigsins daarin geslaag het om in my karakteristiek van die aard van die rol wat die persoonlike daarin speel, 'n korrektief te gec op die beeld wat nog te baie het van ons jonger poësie. Daardie digters is nie blote verheerlikers van 'n individualistiese eie ek nie. Vanuit eie ervaring styg hulle uit tot dinge wat ver buite en bo eie persoonlikheid styg, en verbeeld dit met die uitdrukkingsmiddele wat noodwendig voortvloei uit persoonlike geestesstruktuur. Nie die persoonlikheid staan in die brandpunt nie maar die verbande wat 'n ewige wetmatigheid verkry.

Hierdie kuns is nie die vergestalting van 'n Calvinistiese lewensbeskouing nie, hoewel dit soms verrassende aanrakingspunte daarmee het; dis dikwels nie eens Christelik nie. Maar dit vloei voort uit 'n ernstige eties-religieuse soeke, hoewel die Calvinis daarin telkens die mensgerigtheid nog sal waarneem. Maar wie wil ervaar tot watter profetiese siening 'n nie-Calvinistiese digter kan kom van die sondige mens, van die gevare wat ons in Suid-Afrika bedreig deur ons deel hê aan die geestelike baaierd, van wat die taak van die geestelik lewende mens en die digter is, hoef slegs Blom en Baaierd te lees. Laat ons, by alle bewuste beginselverskil en waaksaamheid ten opsigte daarvan, dankbaar wees vir die positiewe geestelike waardes wat hierdie kuns ons bring.

Uit die aard van die opset moes ek my eensydig tot die konsepsionele .,inhoud' van die kuns bepaal, sonder om wat tog die wesenlike van alle kuns is, die estetiese verwesenliking daarvan te kan aanroer.

Mag ek daarom afsluit met twee gediggies aan te haal wat sou kon gedien het as uitgangspunt om oor die vorm. gewing te praat? 
Die eerste is die klein ,metafisiese voorspel", soos hy dit oorspronklik genoem het, van Van Wyk Louw. 'n Heel eenvoudige verskynsel uit die daaglikse lewe word hier geheimsinnige simbool in gedempte en tog so ekspressiewe verse waarin die flikkering van die kerslig leef, die aanwesigheid van die groot donker, nie as verskrikking nie - dit wil maar tot sy voorsprong, die donker kern in die vlam, terugvloei. Hier is 'n ganse versoende lewensbeeld saamgevat binne die bestek van agt verse:

'n Donker kern in die lig en óm die lig 'n donker sfeer en al die straling is gestuit cn rusteloos en gaan en keer en tas die duister mure af; en al die wêreldwande wíl trug in die kern stort en rus; en alles sterwe sterwe stil.

Teenoor hierdie versoende siening van die dood staan Opperman se verbeelding van sy besef van die verganklikheid in 'n heeltemal ander stylaard, maar nie minder suggestief nie. In hierdie tot uiterste esensie gereduseerde kwatryn gee die digter 'n verontpersoonlikte siening van homself, nee, slegs van een liggaamsdeel wat hy saam met enkele heel persoonlike maar heel gewone gebruiksmiddele as stillewe in 'n spieël weerkaats sien. Uit die doodgewone verse tree ineens die geheimsinnige betekenis te voorskyn met die siening van die ,skedelige" vals tande in 'n glas water:

Die spieël weerkaats 'n stukkie bed en hande, horlosie, kleingeld en kruisbande; en eenkant in ' $n$ glas buig water skedelig om vals tande.

'n Hewig persoonlike belewing, skrik vir die dood na aanleiding van 'n siening van die mees alledaagse dinge, word hier deur verontpersoonliking verhef tot iets universeels. Miskien word wat ek bedoel, duideliker as ons naas hierdie skynbaar so emosielose kwatryn 'n gediggie plaas van Ernst van Heerden wat kennelik onder invloed daarvan ontstaan het en dieselfde titel dra.

Waar Opperman 'n nuwe wêreld skep uit enkele gegewens uit die allergewoonste werklikheid waarin elke woord, elke woord-ding sy geheimsinnige rol speel, 'n wêreld wat voortaan sy eie bestaan sal voer los van die persoon van die skepper daarvan, daar sien ons in Van Heerden se verse die digter nog self aan die werk, beskik om op belkwame wyse te rangskik, om hom self dan af te vra wat hy tot uitdrukking bring en uiteindelik die spel te staak met die skrille kreet van benouensis van die slotkoeplet:

Die stoelrug-skouers dra my jas wat liggaamloos maar onnet pas; ligstrale breek deur vaas en bril: blomoë tot 'n akwarel verstil; die valstandyre - skedellose lag byt diep in glas- en water-skag; met slaappille en Bybelboek reliëf en diepte, hoek tot hoek; die rookspiraal en sigaret versteende offer, dankgebed? Steek dan die hand uit en gee hulp! dic siel is ingeraam on toegeskulp.

G. DEKKER. 